\title{
The bone mass concept: problems in short stature
}

\author{
E Schoenau, C Land, A Stabrey, T Remer ${ }^{1}$ and A Kroke ${ }^{1}$ \\ Children's Hospital, University of Cologne, Josef-Stelzmann-Strasse 9, 50924 Cologne, Germany and ${ }^{1}$ Research Institute of Child Nutrition, \\ Dortmund, Germany \\ (Correspondence should be addressed to E Schoenau; Email: eckhard.schoenau@medizin.uni-koeln.de)
}

\begin{abstract}
Bone densitometry is currently one of the mainstays in the evaluation of systemic bone diseases in adults and is also increasingly used to assess primary or secondary bone disorders in children and adolescents. The purpose of carrying out densitometric studies in such circumstances is to measure the densitometric indicators of bone stability. Following procedures which were established for diagnosing adult osteoporosis, a decrease in densitometric surrogates of bone stability is usually interpreted as indicating increased fracture risk.

The most basic densitometric parameter is bone mineral content (BMC), which can be measured with most densitometric techniques. BMC is either defined as the mass of mineral contained in an entire bone or as the mass of mineral per unit bone length. While mineral mass can be expected to be a good surrogate for bone stability, BMC is obviously a size-dependent parameter, since small bones weigh less than big bones. This is a drawback in paediatric use, since many children and adolescents who are examined by densitometry suffer from chronic disorders and are small-for-age. Short children will have a lower BMC than their healthy age-matched peers, even if their (smaller) bones are otherwise completely normal.
\end{abstract}

European Journal of Endocrinology 151 S87-S91

\section{Introduction}

It is generally accepted that fractures result from low bone mass. Bone mass accounts for $75-85 \%$ of the variance in the ultimate strength of bone tissue, and such measurements also provide an accurate indication of whole bone strength (1).

Most fractures occur late in life, and patients with fractures often have low bone density when compared with age-matched controls $(2,3)$. If low peak bone density is an important contributor to the reduced bone density of fracture patients, then the development of optimal peak bone mass during childhood and adolescence is of crucial importance for the prevention of osteoporosis.

Bone densitometry is a widely used tool for the quantitative assessment of the skeleton. Perhaps the most frequently assessed densitometric parameter at present is areal bone mineral density (aBMD; the mineral mass of bone per unit area of the two-dimensional projection image). This parameter can be measured by dualenergy X-ray absorptiometry (DXA) and is expressed as $\mathrm{g} / \mathrm{cm}^{2}$. However, the main drawback of aBMD in paediatric use is that it is a bone size-dependent measure. For this reason, aBMD is often difficult to interpret in children, because short children will have a lower aBMD than their age-matched peers, even if their smaller bones are otherwise completely normal. In contrast, peripheral quantitative computed tomography (pQCT) allows for unambiguous distinction between the effects of bone size and changes in bone mass per unit volume (volumetric BMD, expressed as $\mathrm{g} / \mathrm{cm}^{3}$ ). pQCT therefore has the potential to improve the diagnostic utility of densitometry in the growing skeleton. The aim of this study was to analyse the influence of height and bone size on the analysis of bone mass and density.

\section{Subjects and methods}

\section{Subjects}

The study population comprised healthy children and adolescents as well as parents. The population has been described in detail in previous studies (4-6). Probands with idiopathic short stature were characterised by height below -2 s.D.

\section{Methods}

Height was measured with an stadiometer. Body mass was measured with a digital electronic scale. Forearm length was measured as the distance between the ulnar styloid process and the olecranon with a calliper. Bone mass and density of the non-dominant side were measured by pQCT at the distal radius (XCT 2000; Stratec Medizintechnik GmbH, Pforzheim, Germany). Bone mineral content (BMC, $\mathrm{mg} / \mathrm{mm}$ ) and BMD (trabecular density, $\mathrm{mg} / \mathrm{cm}^{3}$ ) were automatically analysed from 
the tomographic image with the use of the manufacturer's software as described earlier (4-6).

Determination of muscle area was performed at the non-dominant forearm by use of pQCT as described previously (7).

\section{Results}

Figure 1 shows that children and adults with a height below -2 S.D. have a bone mass which in most cases is

male
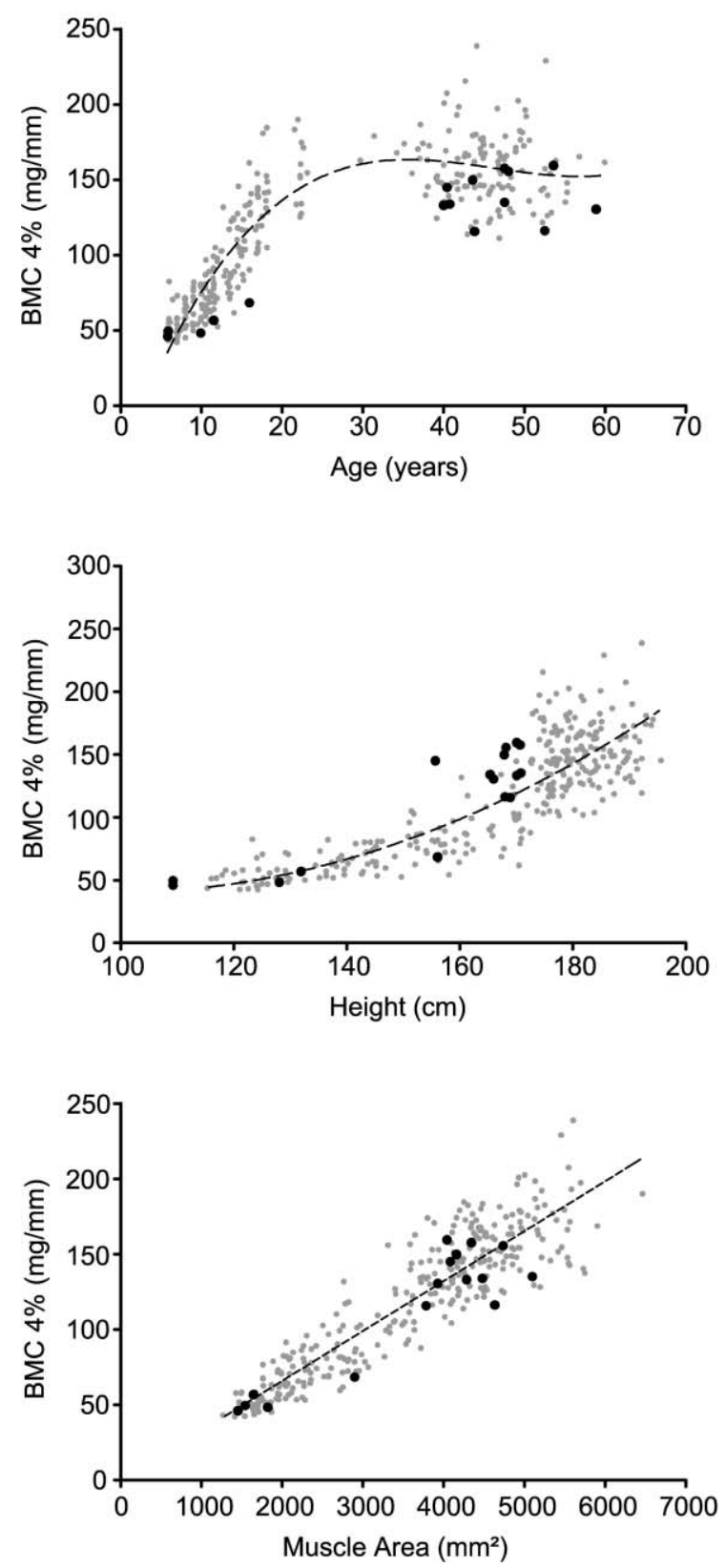

below the regression line of the controls if related to age. In contrast, BMC at the distal radius in short stature related to height and muscle area was not different from the control group. BMC showed the strongest relationship to muscle area in the control group and also in the short-stature group. Trabecular density as a marker of bone density was normally distributed whether related to age, height or muscle area (Fig. 2). Table 1 describes S.D. scores for BMC and trabecular density. Only the mean age-dependent S.D. score for BMC was significently different from zero in the male short-stature group.
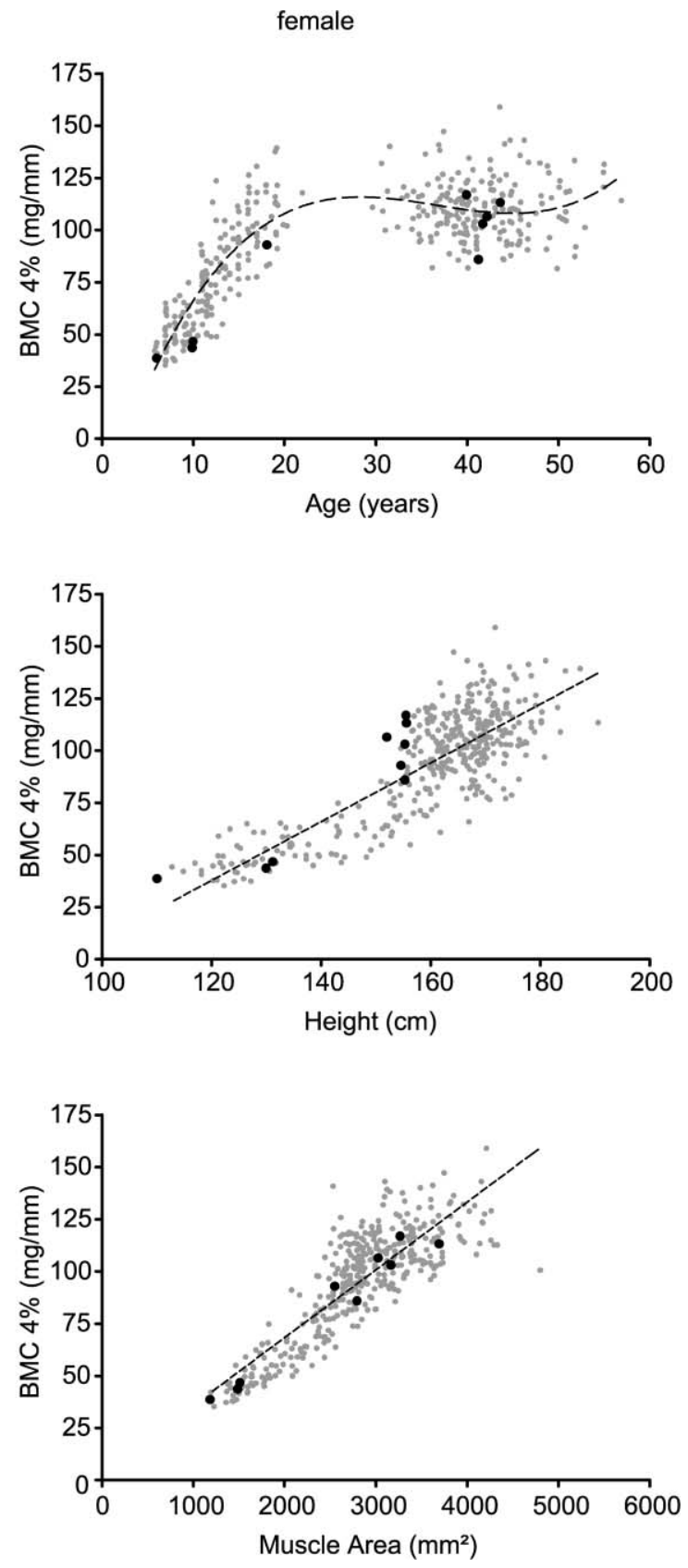

Figure 1 Age, height and muscle dependency of BMC in healthy males and females (grey circles). Probands with short stature (below -2 s.D.) are indicated by solid circles. 

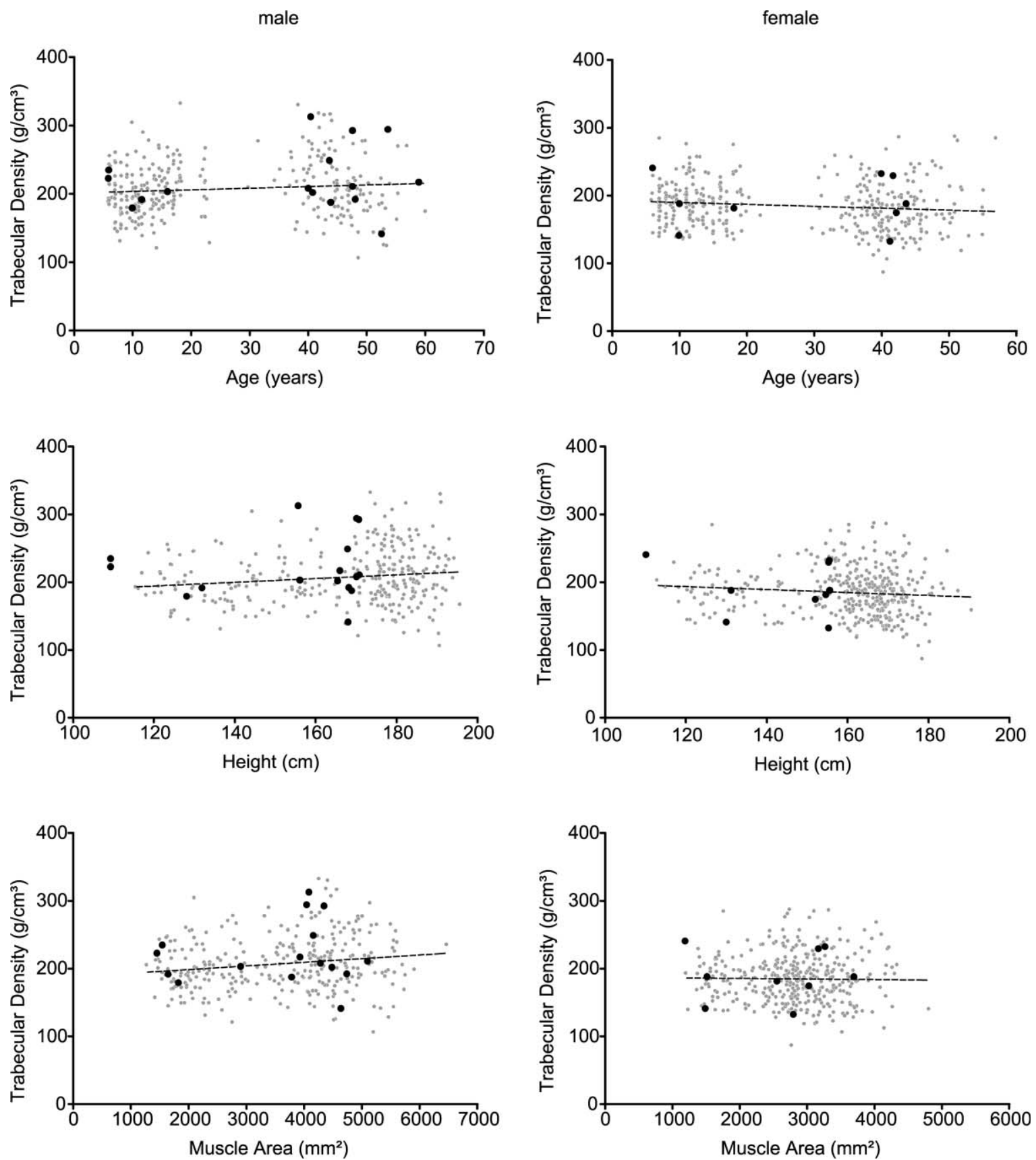

Figure 2 Age, height and muscle dependency of bone density (trabecular density) in healthy males and females (grey circles). Probands with short stature (below -2 S.D.) are indicated by solid circles.

\section{Discussion}

In the past decade there has been considerable interest in the assessment of bone density in children. This has been driven partly by recognition of the fact that the risk of osteoporosis in adults is influenced by peak bone mass which is largely achieved during childhood and adolescence. However, the main reason for such an interest has been the availability of techniques such as DXA because of its speed, precision and low radiation dose. There have been extensive publications reporting DXA in both healthy children and those with a variety of chronic diseases.

However, it is important to remember that DXA is a technique that was originally developed for use in adults, in particular for the diagnosis and management of postmenopausal osteoporosis. Children are not just small adults and therefore the assessment and interpretation of DXA scans in children need to be undertaken with caution. 
Table 1 Results of $\mathrm{PQCT}$ analysis in short stature. Values are mean \pm S.D.

\begin{tabular}{lcr}
\hline & Male $(n=16)$ & Female $(n=9)$ \\
\hline SDS-BMC 4\% & & \\
$\quad$ age & $-1.27( \pm 0.90)^{*}$ & $-0.80( \pm 0.87)$ \\
height & $-0.22( \pm 0.73)$ & $-0.41( \pm 1.01)$ \\
muscle area & $-0.64( \pm 0.66)$ & $-0.47( \pm 0.60)$ \\
SDS-trabecular BMD 4\% & \\
age & $0.07( \pm 0.99)$ & $0.12( \pm 1.16)$ \\
height & $0.42( \pm 1.12)$ & $-0.06( \pm 1.14)$ \\
muscle area & $0.20( \pm 0.92)$ & $0.22( \pm 1.05)$ \\
\hline
\end{tabular}

*Significant difference of score mean value from 0.

It is standard procedure both in paediatrics and in adult medicine to relate many diagnostic parameters to age. However, this is in contrast to recommendations presented by Mazess \& Cameron (8), the developers of single photon absorptiometry. More than 30 years ago, in one of the first bone densitometric studies ever performed in children (8), the authors referred BMC (i.e. the mass of bone mineral) to bone width in order to eliminate the effects of skeletal size (9). These early observations were confirmed by the presented data from our pilot study in short stature. BMC values related to age in idiopathic short-stature patients were often 'artificially' low. The same results on height or muscle function were not different from the control group. In contrast, the analysis of trabecular density was independent of age, height and muscle mass. There was no 'peak density' and no 'peak mass' when related to height and muscle mass. The strongest predictors of bone mass development were height and muscle mass. There was a moderate correlation between age and BMC during childhood. Using agerelated reference data would produce a lot of 'healthy' children with osteopenia. The clinical relevance of this problem in young adults has been demonstrated in patients with constitutional delay of growth and puberty. These patients have a final height in the lower normal range. Using linear absorption techniques in combination with age-related reference data suggested a high risk for osteoporosis (10). However, as reported by Bertelloni et al. (11), bone mass deficit of these patient disappears when results are corrected for body height or bone size. Similar effects have been described in children with renal failure and transplantation (12). Gafni \& Baron (13) described the 'overdiagnosis' of osteoporosis in children in a recently published paper in more detail (13).

How, then, can densitometric data in children and adolescents be evaluated in a rational way? We propose a functional approach to this fundamental problem. which takes into account the balance between bone strength and the forces which normally challenge bone stability. The largest physiological loads on a bone result from muscle contraction (14, 15). Even during everyday activities muscle contraction routinely puts much larger loads on the skeleton than the simple effect of gravity, because muscles have to move the body around by using quite unfavourable lever arms (14, 15). Bone stability therefore needs to be adapted to muscle force. This functional muscle-bone relationship could be used for diagnostic purposes, when densitometric surrogates of bone strength are compared with indictors of muscle force.

When the musculo-skeletal system is thus analysed as a functional unit, the question arises as to how "normality' should be defined. Bone strength may be adequately adapted to local muscle force but, if muscle force is abnormally low, this means that bone strength is also decreased. With regard to the application of the muscle-bone relationship to clinical practice, we propose the two-step diagnostic algorithm shown in Fig. 3. A measure of muscle force or size and a measure of BMC at a corresponding location are required. The results can be combined into four diagnostic groups. In the first situation, muscle force or size adequate for height: if $\mathrm{BMC}$ is adapted normally to the muscle system, the result is interpreted as 'normal' but if $\mathrm{BMC}$ is lower than expected for muscle force or size, a 'primary bone defect' is diagnosed. In the second situation, muscle force or size is too low for height: even

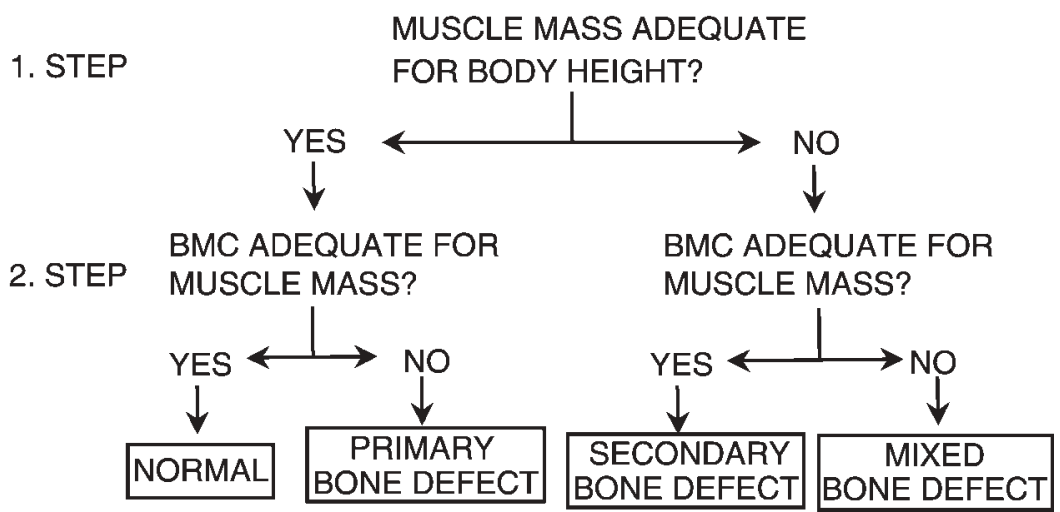

Figure 3 Proposed diagnostic algorithm for osteoporosis. (Reprinted, with permission of the American Society for Bone and Mineral Research, from (16).) 
if BMC is adequately adapted to the decreased mechanical challenge, this means that bone mass and presumably strength are still too low for body height and therefore a 'secondary bone defect' is diagnosed. If muscle force or size are abnormally low and BMC is even lower than expected from a normal musclebone relationship, a 'mixed bone defect' (primary and secondary) is present (16).

Based on such simple ideas, it can be reasonably suggested that analyses of bone mass (and bone structure) should focus on the question of whether they are adequate for bone function. The main purpose of bones is to provide enough strength (not merely enough mass) to keep voluntary physical loads from causing spontaneous fractures, regardless of whether these loads are chronically subnormal (as in inactivity or muscle disorders), normal or supranormal. This concept has been recommended recently by Ward \& Glorieux (17): 'Osteoporosis will be said to exist when the skeleton has not been able to withstand its mechanical challenges (growth and muscle force) due to inadequate bone mass and/or structure, resulting in atraumatic fractures. This means that a child will not be labelled with osteoporosis unless there is a history of fractures that occur with minimal trauma. With such an approach, the term osteopenia will not be employed in the assessment of a child's bone health.'

\section{References}

1 Kanis JA, Melton LJ, Christiansen C, Johnston CC \& Khaltaev N. The diagnosis of osteoporosis. Journal of Bone and Mineral Research $199491137-1141$.

2 Mazess RB. On aging bone loss. Clinical Orthopedics 1982165 239-252.

3 Riggs BL \& Melton LJ 3rd. Involutional osteoporosis. New England Journal of Medicine $1986 \mathbf{3 1 4} 1676-1686$.

4 Neu CM, Manz F, Rauch F, Merkel A \& Schoenau E. Bone densities and bone size at the distal radius in healthy children and adolescents: a study using peripheral quantitative computed tomography. Bone 200128 227-232.

5 Neu CM, Rauch F, Manz F \& Schoenau E. Modeling of cross-sectional bone size, mass and geometry at the proximal radius: a study of normal bone development using peripheral quantitative computed tomography. Osteoporosis International $200112538-547$.

6 Schoenau E, Neu CM, Mokov E, Wassmer G \& Manz F. Influence of puberty on muscle area and cortical bone area of the forearm in boys and girls. Journal of Clinical Endocrinology and Metabolism 200085 1095-1098.

7 Neu CM, Rauch F, Rittweger J, Manz F \& Schoenau E. Influence of puberty on muscle development at the forearm. American Journal of Physiology. Endocrinology and Metabolism $2002 \mathbf{2 8 3}$ E103-E107.

8 Mazess RB \& Cameron JR. Skeletal growth in school children: maturation and bone mass. American Journal of Physical Anthropology $197135399-407$.

9 Garn SM \& Wagner B. The adolescent growth of the skeletal mass and its implications to mineral requirements. In Adolescent Nutrition and Growth, ch. 11, pp 139-161. New York: Appleton-Century Crofts, 1969.

10 Finkelstein JS, Neer RM, Biller BM, Crawford JD \& Klibanski A. Osteopenia in men with a history of delayed puberty. New England Journal of Medicine 1992326 600-604.

11 Bertelloni S, Baroncelli GI, Ferdeghini M, Perri G \& Saggese G. Normal volumetric bone mineral density and bone turnover in young men with histories of constitutional delay of puberty. Journal of Clinical Endocrinology and Metabolism $1998 \mathbf{8 3} 4280-4283$.

12 Reusz GS, Szabo AJ, Peter F, Kenesei E, Sallay P, Latta K, Szabo A, Szabo A \& Tulassay T. Bone metabolism and mineral density following renal transplantation. Archives of Diseases in Childhood 200083 146-151.

13 Gafni RI \& Baron J. Overdiagnosis of osteoporosis in children due to misinterpretation of dual-energy x-ray absorptiometry (DEXA). Journal of Pediatrics $2004144253-257$.

14 Burr DB. Muscle strength, bone mass, and age-related bone loss. Journal of Bone and Mineral Research 199712 1547-1551.

15 Martin RB, Burr DB \& Shrkey NA. Skeletal Tissue Mechanics. New York: Springer Verlag, 1998.

16 Schoenau E, Neu CM, Beck B, Manz F \& Rauch F. Bone mineral content per muscle cross-sectional area as an index of the functional muscle-bone unit. Journal of Bone and Mineral Research 200217 1095-1101.

17 Ward LM \& Glorieux FH. The spectrum of pediatric osteoporosis. In Pediatric Bone Biology and Disease, pp 401-442. Eds J Glorieux, J Pettifor \& H Jueppner H. New York: Academic Press, 2003.

Received 16 February 2004

Accepted 19 April 2004 